\title{
11 The road to Arkham Asylum
}

\author{
Batman: Dark Tomorrow and \\ transitional transmedia
}

James Fleury

The period of 1997 to 2005 represented a branding crisis for the Batman intellectual property (IP), or brand. During this time, Warner Bros., DC Comics, and their conglomerate parents Time Warner and AOL Time Warner struggled to revive the character as a film franchise after the disappointing critical and commercial performance of Batman and Robin (1997). ${ }^{1}$ Prior to the reboot Batman Begins (2005), Batman continued to appear in comic books (e.g., crossover arcs such as 1999's "No Man's Land") and animated television series (e.g., Justice League [2001-2004]). This left Time Warner and AOL Time Warner without a theatrical film release capable of powering a "synergy" campaign, where they could use different corporate holdings to cross-promote one another.

Dating back to Superman: The Movie (1978), the conglomerate then known as Warner Communications Inc. (WCI) - which became Time Warner in 1990, after merging with Time Inc.-had used its comic book IP as the basis for synergistic films. Superman: The Movie not only adapted an internal IP, but it also demonstrated to WCI the cost efficiency of repurposing a product across its divisions. The film drew from and added to DC Comics stories while also inspiring a Warner Bros. Records soundtrack, tie-ins from Warner Books, and a 1978 Atari videogame. ${ }^{2}$ The game, with a plot that loosely adapts a sequence from the film-in which an earthquake endangers a bridge- but with promotional art taken from the comics, reflects a dual licensing strategy involving separate rights to Superman: The Movie and the comics (see Figure 11.1).

This allowed WCI to collect a greater portion of the comics-licensing profits compared to the film-licensing rights that were shared with independent producers Alexander and Ilya Salkind (Screen International 1978, 12). As Eileen Meehan $(2015,78)$ has analyzed, WCI took a similar approach with Batman (1989), with Warner Bros. licensing out the film rights and DC licensing out rights to the character's comics incarnation. As part of this dual licensing strategy, Sunsoft published a pair of multiplatform videogame tie-ins: 1990's Batman: The Video Game, which adapted the film's narrative, and 1991's Batman: Return of the Joker, whose licensing from DC Comics—and not Warner Bros.-positioned it as a sequel to the 


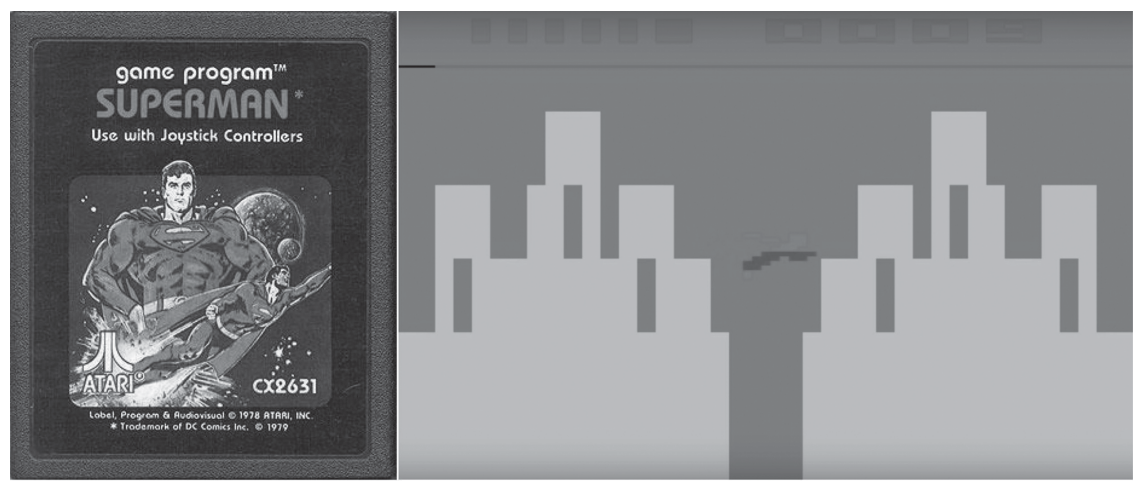

Figure 11.1 Dual film and comic book licensing in Superman (1978) (composite by the author).

1990 game rather than to the film despite using the film's font and vehicular designs (see Figure 11.2).

The licensing program for the sequels Batman Returns (1992), Batman Forever (1995), and Batman and Robin focused more on the films themselves. As such, the tie-in videogames-from publishers Acclaim Entertainment, Atari, Konami, Sega, and Tiger Electronics—all adapted their respective film's plot, characters, and settings. By the late 1990s, tie-in games had become an expected component of a film's network of ancillary, or paratextual, material. With the cinematic future of Batman in limbo after Batman and Robin, Time Warner and AOL Time Warner returned to a dual licensing strategy to maintain the IP's gaming presence. First, Warner Bros. partnered with publishers on games set in the "DC Animated Universe." Ubisoft, for instance, released Batman: Vengeance in 2001 and Batman: Rise of Sin Tzu two years later, with each featuring an original story set in the world of The New Batman Adventures animated series (1997-1999). Second, DC Comics separately licensed out the rights for comics-based games, including 2003's Batman: Dark Tomorrow from publisher Kemco and developer Hot Gen. Like Ubisoft's titles, Batman: Dark Tomorrow presents a new story, one whose characters and storyworld derive from the comics and that extends into a two-issue series. Then, in 2004, Warner Bros. formed the Warner Bros. Interactive Entertainment (WBIE) videogame subsidiary, which has embraced in-house development and publishing over licensing partnerships while also focusing on Batman games not tied to other media, such as the LEGO Batman (2008-), Injustice (2013-), and Arkhamverse (2009-2016) transmedia franchises.

As Batman: Vengeance, Batman: Rise of Sin Tzu, and Batman: Dark Tomorrow all suggest, the positioning of licensed videogames-whether created internally by the IP owner or externally by a vendor-had started 


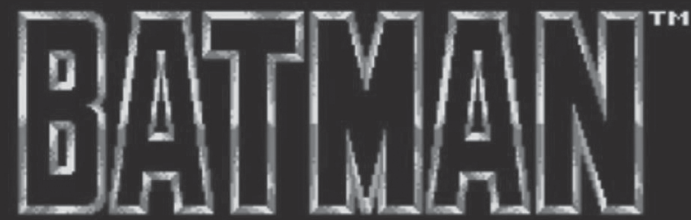

\section{Return of The Joker ${ }^{\text {TH }}$}
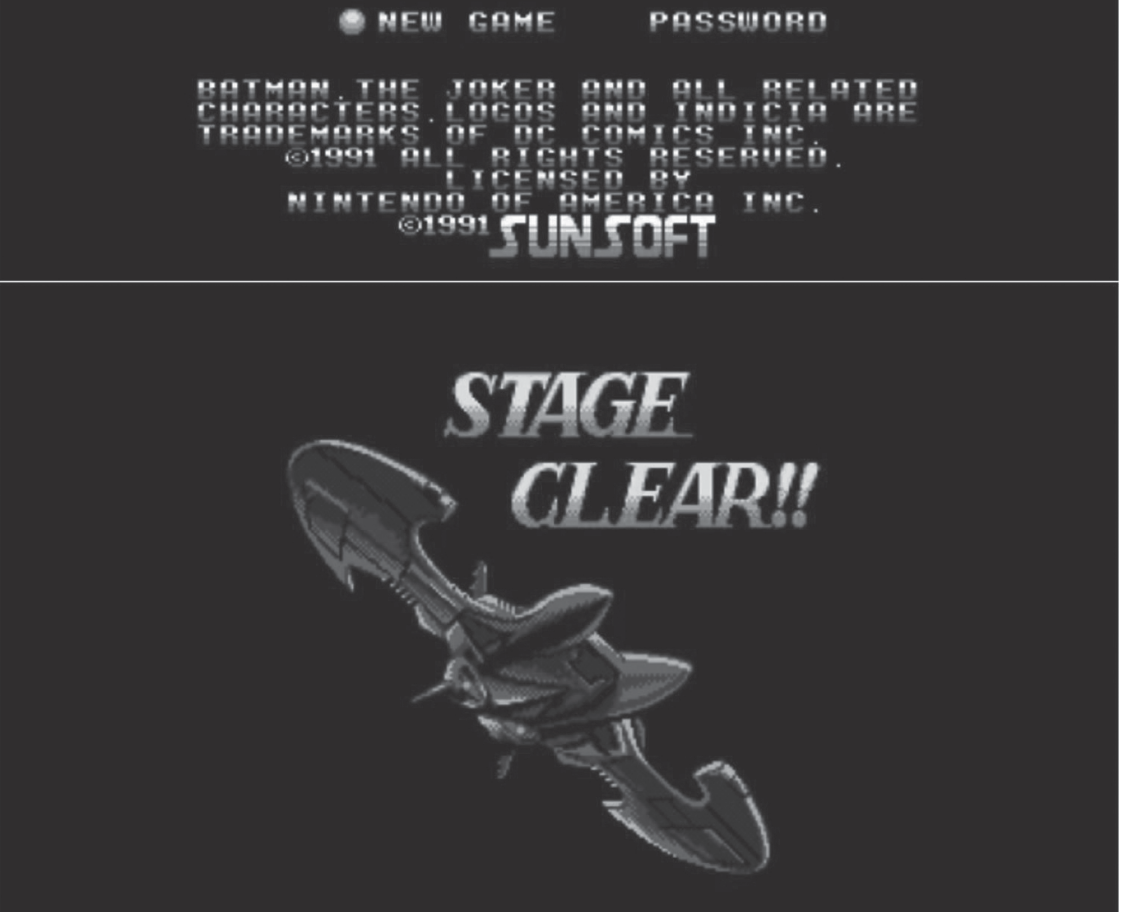

Figure 11.2 Comic book licensing combined with film elements in Batman: Return of the Joker (1991) (composite by the author).

to shift from "multimedia" to "transmedia" by the early 2000s. That is, whereas earlier Batman tie-ins had replicated film narratives, these newer games expanded the storyworlds of their respective franchise. More recently, as WBIE's Batman projects demonstrate, licensed games have shifted even further away from replication; instead of adapting elements from a single text (e.g., a film, TV show, or comic book arc), LEGO Batman, Injustice, and the Arkhamverse adapt elements from multiple texts to present amalgamated, unique interpretations of Batman that have inspired their own distinct franchises. 
In this chapter, I analyze how Batman: Dark Tomorrow reflects changes in tie-in videogame production in the early 2000s and also prefigures the transmedia storytelling framework of the Arkhamverse franchise that began with Batman: Arkham Asylum (2009). While Batman: Dark Tomorrow anchored itself to the comic books, Batman: Arkham Asylum arrived in a different gaming landscape and consolidated elements from across the history of Batman media, including not just the comics but also the film and TV incarnations. Both games express how media franchises have turned to paratexts to sustain IP in between film releases, with Batman: Dark Tomorrow debuting prior to Batman Begins and Batman: Arkham Asylum arriving in between The Dark Knight (2008) and The Dark Knight Rises (2012). After providing an overview of developments in scholarly and management approaches to transmedia storytelling, I examine how the Batman IP represents a complex web of multiple-sometimes intersecting, sometimes isolated-franchises. I then analyze the transmedia elements of Batman: Dark Tomorrow before concluding with an exploration as to why Batman: Arkham Asylum went on to receive a decidedly more enthusiastic response from critics and audiences. Together, these games demonstrate that efforts to implement transmedia storytelling in relation to Batman have proven challenging due to the IP's multifranchisality. Based on a political economy of the media perspective and close readings of the games themselves, I argue that the difference in reception for Batman: Dark Tomorrow and Batman: Arkham Asylum lies in a combination of adaptation approaches and changes in managing media industry convergence.

\section{Approaches to studying and franchising Batman}

Developments in transmedia studies and media franchise management have followed a similar path of prioritizing narrative development before focusing on "storyworld" development. Introduced in Marsha Kinder's Playing with Power in Television, Movies and Video Games: From Muppet Babies to Teenage Mutant Ninja Turtles (1991), the concept of transmedia storytelling-as Henry Jenkins defines it in Convergence Culture: Where Old and New Media Collide-refers to a narrative that "unfolds across multiple media platforms, with each new text making a distinctive and valuable contribution to the whole" (2006, 97-98). Jenkins argues that transmedia storytelling represents "a new aesthetic that has emerged in response to media convergence" (Jenkins 2006, 20-21). By convergence, he means "a situation in which multiple media systems coexist and where media content flows fluidly across them" $(2006,20,322)$. Whereas Jenkins focuses on late-twentieth and early-twenty-first-century examples of convergence, encouraged by then-emergent technologies like the internet and mobile devices, Avi Santo (2015) as well as Kristin Fast and Henrik Örnebring (2017) have reminded us that pre-digital media convergence also supported an industrial strategy of transmedia (e.g., introduced on the 
radio in 1930, The Shadow brought together pulp magazines, comic strips, and film shorts).

In addition to exploring the analogue origins of transmedia, scholarsincluding Jenkins himself-have expanded their attention from narratives carried across media texts to the development of storyworlds across media texts (Ryan and Thon 2014, 1). Based on this more recent scholarship, Matthew Freeman has defined transmedia storytelling as a set of industry "strategies for holding fictional story worlds [sic] together across multiple media and for pointing audiences across those media" $(2016,3)$. This definition encourages a more expansive view of transmedia not just for scholars but also for industry practitioners. In the narrative-centric model of transmedia, as Jenkins puts it, "each medium does what it does best," and "[e]ach franchise entry needs to be self-contained" without being redundant. However, even he describes this as an "ideal form of transmedia storytelling" (Jenkins 2006, 98). To achieve this "ideal," creative stakeholders (e.g., the IP owner and any licensees), according to Fast and Örnebring, need to take a "planned (i.e., strategic, coordinated)" $(2017,637)$ approach. Prioritizing the expansion of a storyworld instead of a narrative, though, leaves more room for an "emergent (i.e., unplanned, contingent, organic)" approach that can better respond to creative developments and market trends while also encouraging closer engagement with the audience, permitting, for instance, fan contributions to media franchises (Fast and Örnebring 2017, 637).

For scholars, broadening the focus from narrative-building to worldbuilding takes account of not only the value of fan practices (e.g., as Marta Boni explains, digital technologies have underscored the extent to which "textual poaching, participatory culture and sharing activities can also complement official marketing strategies" [2017, 18]) but also the practical challenges of coordinating transmedia campaigns. In the introduction to their edited collection Star Wars and the History of Transmedia Storytelling (2017), Sean Guynes and Dan Hassler-Forest write regarding the collection's essays: "While it may seem as though transmedia franchises such as Star Wars have become all-powerful entertainment empires, these analyses of key moments show how precarious, unpredictable, and strangely unstable the Star Wars storyworld has truly been" $(2017,13)$. Studying world-building instead of just narrative, then, helps draw attention to the difficulties of establishing and sustaining transmedia franchises. If the narrative-based form of transmedia assumes a "top-down" model in which rights-owners exercise complete control, the more expansive perspective of world-building acknowledges their lack of control. ${ }^{3}$

In fact, the shift from multimedia to transmedia represents a franchise management strategy designed to compensate for this lack of control. As I have discussed elsewhere (with Bryan Hikari Hartzheim and Stephen Mamber), multimedia involves texts that "adapt shared material (e.g., a novelization or tie-in videogame that retells a film's story)" whereas transmedia texts deliver "different material so that the totality of a franchise presents 
an overarching story" (Fleury et al. 2019, 1). In general, moving from multimedia to transmedia management helps IP owners "create heightened interest across their brands [...] in response to shifting audience and technological trends" (Fleury et al. 2019, 1). Tie-in videogames, for example, moved from multimedia replication to transmedia expansion to address changes in consumer taste and hardware developments.

Typically released in time for a film's theatrical opening weekend or arrival on home video, tie-ins are designed to leverage the accompanying marketing budget and provide cross-promotion. By the 1990s, technological advancements (e.g., more photorealistic graphics and higher-capacity memory) encouraged games that could more faithfully recreate the look, sound, and scope of a given film at the expense of a longer development period. At the same time, tie-in developers have tended to struggle with limited access to film material like scripts and footage, which has restricted the ability for tie-ins to provide a faithful adaptation. This limited access and the increasingly long time needed for development made it difficult for tie-ins to appear in time for a film's theatrical or home video release date without sacrificing gameplay or presentation quality. As a result, tie-ins that directly adapted a film's narrative developed a negative reputation among players and critics. ${ }^{4}$ A compensatory trend that became especially common in the 2000s, fewer tie-ins adapted film narratives and instead began to present original stories (e.g., sequels and prequels) set in the same world. Transmedia, then, allowed for tie-ins to still exploit a film's accompanying publicity without needing to gain access to a script or footage. With no new Batman films at the time, Batman: Dark Tomorrow served as the main text, or what Jenkins (2014) has called the "mothership," of its own transmedia constellation connected to the franchise's comics.

By the end of the 2000s, tie-ins had begun to migrate from home consoles (e.g., Microsoft's Xbox and Sony's PlayStation hardware) to mobile platforms (i.e., smartphones and tablets). For developers and IP owners, mobile devices allow for faster and less expensive development so that games can more easily arrive in time for a film release. For consumers, the low, or even free (with "in-app purchases"), download cost of these apps presents a lower barrier to entry than a $\$ 60$ console game (Kohler 2013). Despite the film tie-in market moving more and more to mobile, consoles continue to receive licensed games. Unlike multimedia and transmedia products that directly adapt a film's elements, games such as those within the Arkhamverse take a more "general" approach that uses a nonspecific version of an IP.

This approach simultaneously promotes a larger media brand, rather than just a single film of that brand, and can serve as the foundation for a new transmedia franchise in its own right. Although these general licensed games do not directly adapt specific aspects of other franchise texts, they still function as world-building for an IP. As such, they avoid some of the problems associated with transmedia tie-ins to films, such as a tendency for subsequent film releases to supersede the contributions of paratexts 
(e.g., The Amazing Spider-Man 2 [2014] presents a version of the Rhino [played by Paul Giamatti] that contradicts the characterization from the previous tie-in game The Amazing Spider-Man [2012]). As Freeman notes, when focused on extending a narrative rather than a world, "transmedia storytelling is often a messy system of contingencies, alternatives, and reboots" $(2017,63)$. By not adding to a film's narrative, general licensed games follow what Jenkins describes as a transmedia storytelling trend in which continuity matters less than "multiplicity-the possibility of alternative versions of the characters or parallel universe versions of the stories" (2009b, n.p.). As Clare Parody puts it, multiplicity is "often a rewarding form of mastery over a franchise text, not a source of tension" $(2011,216)$. General licensed games, then, present a new version of an IP not beholden to the expectations of other media texts. With Batman, Batman: Dark Tomorrow represents an early attempt at this generic concept, albeit one still tied to the character's comic books; subsequently, Batman: Arkham Asylum would deviate from any single pre-existing version of Batman while inspiring its own, Arkhamverse transmedia storyworld.

Based on these shifts in franchise management in general and tie-in game approaches in particular, I propose a model that seeks to make sense of the seemingly multiple Batman franchises. Back in 1991, William Uricchio and Roberta E. Pearson (2015) analyzed how, throughout the late 1980s, the Batman franchise had noticeably splintered, transitioning from an organizational logic of continuity to one of multiplicity due to the economic strategy of synergy-which, as in the case of Superman: The Movie, encouraged variations of the same IP. For decades, the Batman comics already had presented a continuity distinct from other media (e.g., the TV series Batman [1966-1968]), and this practice continued with the film franchise that began in 1989. However, by the late 1980s, the comics no longer shared a single continuity; instead, standalone mini-series like The Dark Knight Returns (1986) and one-shots like Batman: Gotham by Gaslight (1989) presented narratives set outside the "canon" of the comics. This splintering prompted Uricchio and Pearson to observe that, because Batman lacks a "primary urtext," multiple versions of the character tend to exist simultaneously at any given time $(2015,207)$. As Jenkins has noted, "rather than fragmenting or confusing the audience, this multiplicity of Batmen helped fans learn to live in a universe where there were diverse, competing images of their favorite characters and indeed, to appreciate the pleasures of seeing familiar fictions transformed in unpredicted ways" (2009a, n.p.). Over time, the concept of multiplicity has become a common practice within the comic book industry, especially as a way to attract new consumers and offer novelty to existing fans (Pearson 2017, 121).

Because of this, there now exist multiple "Batmen," each of which, I contend, comprise a different franchise. To organize the network of Batman texts, I draw from Nick Browne's "The Political Economy of the Television (Super) Text" (1984). Browne (1984, 176-180) presents several ways to 


\begin{tabular}{l|l|l}
\multicolumn{1}{c|}{ Category } & \multicolumn{1}{c|}{ Description } & \multicolumn{1}{c}{ Examples } \\
\hline Megatext & $\begin{array}{l}\text { Everything featuring elements } \\
\text { of the Batman intellectual } \\
\text { property, whether licensed or } \\
\text { unlicensed }\end{array}$ & $\begin{array}{l}\text { All Batman comic books, } \\
\text { films, video games, animated } \\
\text { series, fan fiction }\end{array}$ \\
\hline Supertext & $\begin{array}{l}\text { Each Batman franchise, } \\
\text { whether licensed or } \\
\text { unlicensed }\end{array}$ & $\begin{array}{l}\text { The Dark Knight trilogy, the } \\
\text { Arkhamverse }\end{array}$ \\
\hline Individual texts & $\begin{array}{l}\text { Each Batman franchise text, } \\
\text { whether licensed or } \\
\text { unlicensed }\end{array}$ & $\begin{array}{l}\text { Batman (Tim Burton, 1989), } \\
\text { Batman: Dead End (Sandy } \\
\text { Collora, 2003) }\end{array}$
\end{tabular}

Figure 11.3 Categories of Batman texts, derived from Nick Browne's "The Political Economy of the Television (Super) Text” (1984).

describe a "television text" and its "context," from the "megatext" ("the text of television," or "everything that has appeared on television") to the "supertext" " the particular program and all the introductory and interstitial materials," such as advertisements) to "the program proper" (e.g., individual TV series). I apply this framework to distinguish between the Batman "megatext" (everything featuring elements of the IP, whether licensed or unlicensed), Batman "supertexts" (individual Batman franchises, such as the Arkhamverse), and individual texts (e.g., each film) (see Figure 11.3). In addition to accounting for IP-owner and audience contributions as well as for overlaps between the categories, this model also helps to emphasize the distinction between the franchise management strategies of Batman: Dark Tomorrow and Batman: Arkham Asylum.

\section{The transmedia "failure" of Batman: Dark Tomorrow and the transmedia "success" of Batman: Arkham Asylum}

Having splintered in the 1980s, the Batman megatext between 1997 and 2005 followed a trend of dormant film brands embracing paratexts as a form of franchise management. In 1991, Timothy Zahn's novel Heir to the Empire had reinvigorated interest in Star Wars during the cinematically fallow period between Star Wars Episode VI: Return of the Jedi (1983) and Star Wars Episode I: The Phantom Menace (1999). More broadly, Zahn's novel popularized the "Expanded Universe" concept, in which paratexts contribute to a larger narrative and storyworld. This model depends on the transmedia integration of multiple platforms to sustain a single, grand story and world. Compared to Star Wars, however, industrial and textual circumstances have limited the ability of the Batman brand to embrace a similar, overarching transmedia model. 


\section{J. Fleury}

Specifically, the larger Batman megatext comprises multiple transmedia supertexts, including not just the Arkhamverse but also, for instance, the DC Animated Universe and Injustice. As the dual licensing strategy between Warner Bros. and DC for Superman: The Movie and the 1989 Batman film suggests, divisions in the Warner conglomerates historically have competed, rather than cooperated, with each other. This extends from a corporate practice of Warner "siloing" its units to provide each with greater flexibility against the volatile nature of the market for their respective products (Flint 2019; Littleton 2013). Furthermore, whereas Star Wars revolves around its films, the Batman IP has long maintained a distinct presence in different media, which has created a decentralized constellation of texts. That is, while the films drive the transmedia storytelling for Star Wars, the Batman megatext includes multiple, unrelated supertexts, or different sub-franchises within the larger franchise. As Time Warner, AOL Time Warner, and AT\&T have horizontally and vertically expanded across media, these sub-franchises have transitioned from a multimedia format-in which paratexts repeat the narratives of a source text- to a transmedia model-in which paratexts contribute unique narrative and world-building material and enrich one another. Batman: Dark Tomorrow and Batman: Arkham Asylum demonstrate how the Batman megatext gradually adopted a transmedia model for its supertexts as a management strategy to sustain audience interest in between film releases.

Despite its rather limited multiplatform storytelling and negative reception, Batman: Dark Tomorrow paved the road to the Arkhamverse transmedia franchise due to its independence from the Batman films and TV series. Throughout the 1990s, few superhero films appeared outside of the four live-action Batman installments due to the troubled development on a new Superman film and rights complications on Marvel adaptations. While Batman appeared only in games tied to either the films or Batman: The Animated Series (1992-1995), other superheroes headlined games based on both their animated and comics incarnations, with some even adapting specific comic book arcs (e.g., The Death and Return of Superman [1994] and Spider-Man and Venom: Maximum Carnage [1994]). In the early 2000s, as Warner Bros. continued to struggle with launching new superhero films, DC chose to capitalize on its characters. This led to licensed games that adapted general comic book elements (e.g., characters, settings, and art styles) without adapting specific stories, including Superman: The Man of Steel (2002), Aquaman: Battle for Atlantis (2003), and Batman: Dark Tomorrow.

Batman: Dark Tomorrow, in fact, represented the first Batman videogame to have no film or TV ties since the comics-licensed Batman: The Caped Crusader (1988). As a press release put it, "'Batman: Dark Tomorrow' is the first modern Batman video game to date based not on the movie or animation series, but on the original DC Comics comic book" (Kombo 2012, n.p.). To distinguish Batman: Dark Tomorrow from recent Batman games, Kemco 
leaned into the DC Comics license. To compensate for the lack of a source film, the publisher hired comics veteran Scott Peterson-who, at the time, was writing Batman: Gotham Adventures for DC-and Kenji Terada-the co-writer of the first three installments of the Final Fantasy series (19871990) — to develop the script. Notably, Batman: Dark Tomorrow represents one of the first games to come from a comics writer. This continued a trend at the time of publishers partnering with creative stakeholders from other media to add legitimacy to their licensed products, such as the participation of actors Tobey Maguire and Willem Dafoe in the film tie-in Spider-Man (2002) or the involvement of the Wachowskis in the transmedia text Enter the Matrix (2003). With a script from writers associated with comics and videogames, Batman: Dark Tomorrow distinguishes itself from previous, film- and TV-based Batman titles (see Figure 11.4).

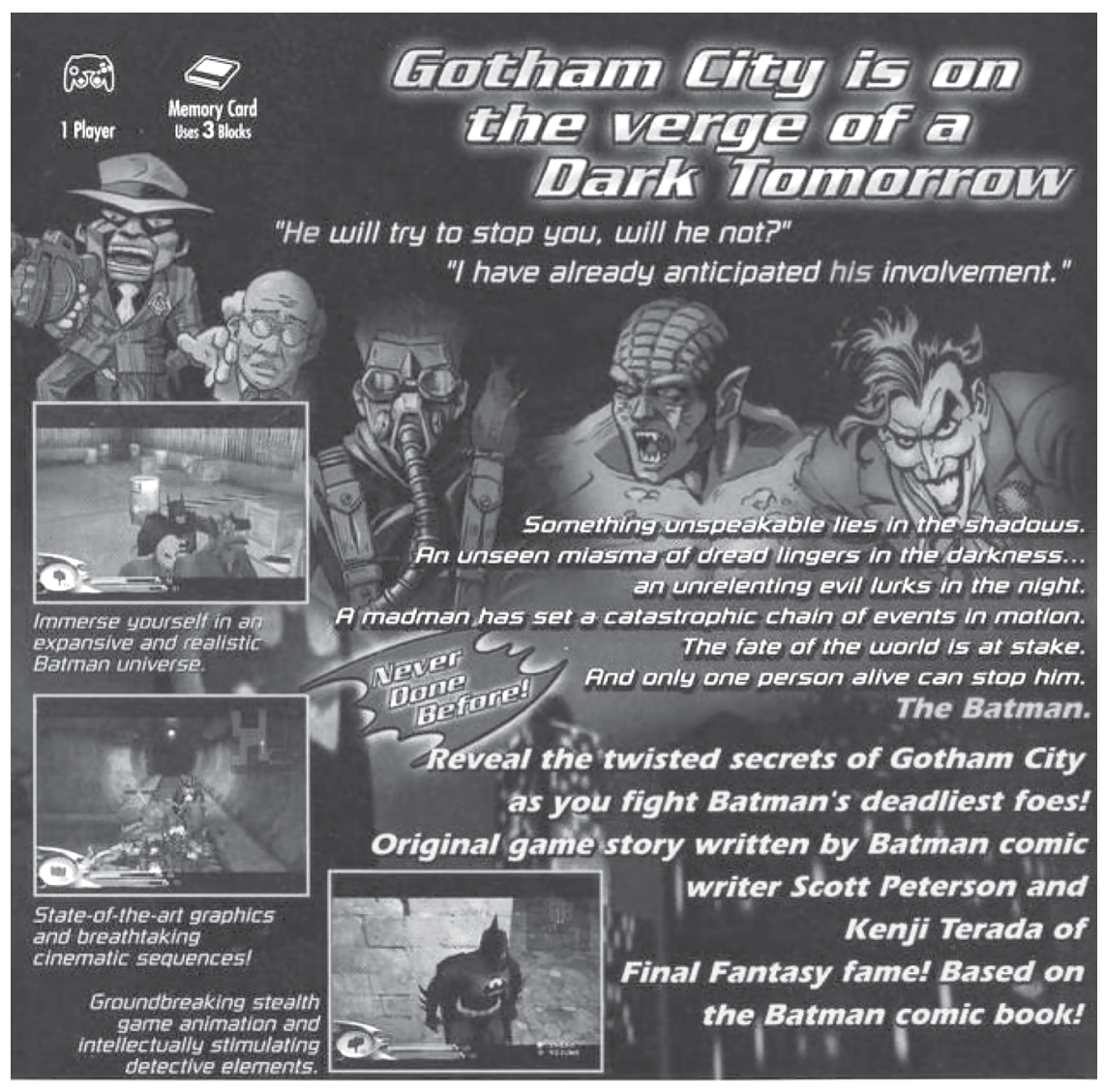

Figure 11.4 The packaging for Batman: Dark Tomorrow (2003) emphasizes its ties to the comic books. 


\section{J. Fleury}

The story itself also works to appeal to multiple demographics. It begins with Batman attempting to thwart a gang war between the Ventriloquist, Scarface, and Black Mask while the Joker abducts Commissioner Gordon and holds him hostage at Arkham Asylum. To rescue Gordon, the playeras Batman-must defeat a series of enemies like Poison Ivy, Killer Croc, and Mr. Freeze. Batman eventually discovers that Ra's al Ghul had orchestrated the kidnapping as a distraction from his plot to dominate the world by detonating a number of bombs that will cause natural disasters. As this summary suggests, the story relies on encounters with characters familiar to film audiences as well as characters better known among comics aficionados. With appeals to general audiences, comic book readers, and gaming enthusiasts alike, the game provides several levels of access and meaning. ${ }^{5}$

To expand the game's appeal beyond comic book fans, Kemco also took advantage of the promotional hype machine that powers the videogame industry press. Batman: Dark Tomorrow received a considerably warm reception at the 2001 edition of the Electronic Entertainment Expo (E3) trade show, where the publisher announced the project's pedigree of comics and gaming talent and also showcased a non-playable demo featuring computer-animated cutscenes (see Figure 11.5).

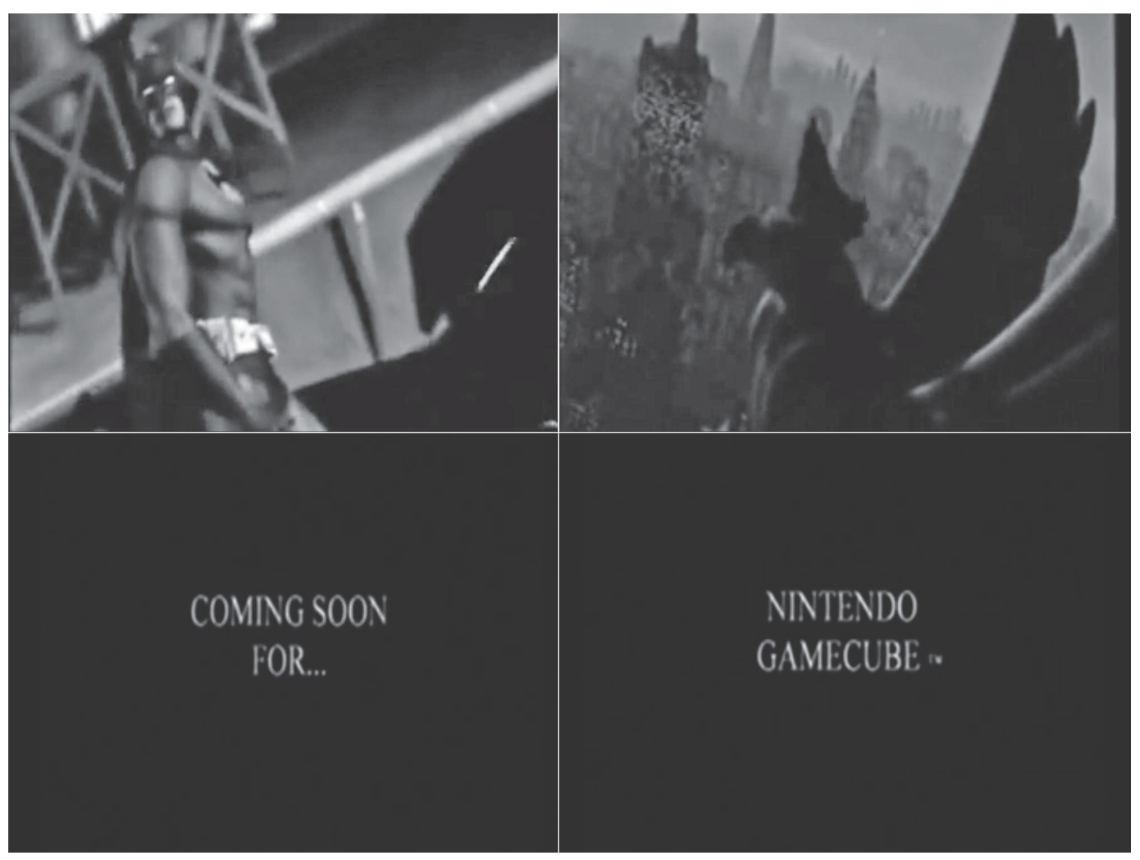

Figure 11.5 Images from the 2001 E3 preview of Batman: Dark Tomorrow (composite by the author). 
This trailer, however, provided no indication of what the playable portions of the game would look like. This speaks to the emphasis placed on visuals at the time among the gaming press in anticipation of the Fall 2001 releases of the Microsoft Xbox and Nintendo GameCube-consoles that, like the Sony PlayStation 2 that had debuted a year earlier, could achieve more photorealistic graphics than earlier hardware. Justin Speer of GameSpot, for instance, wrote the following about the Batman: Dark Tomorrow preview video: "While no obvious gameplay elements were demonstrated, beautiful action-packed cutscenes gave proof of the GameCube's rendering power" (2006, n.p.). Although game industry previews allow us to chart a game's development, they tend to be tightly controlled and misleading experiences (Pitts 2016). ${ }^{6}$ This often results in published previews that resemble thinly veiled promotions. In the case of Batman: Dark Tomorrow, Kemco's focus on production values worked to create an aura of prestige around the visuals and talent involved.

By not highlighting actual gameplay, the publisher withheld a series of problems plaguing the project's development. After announcing Batman: Dark Tomorrow as a GameCube exclusive that would arrive in November 2001, Kemco expanded development to the Xbox. Once Microsoft became involved, the company demanded changes to the story and gameplay. This delayed the development process, with Peterson needing to provide rewrites and developer Hot Gen needing to make gameplay and presentation compromises in order to meet the demands of a growing list of stakeholders that included Kemco, Nintendo, Microsoft, and DC. Ultimately, by the time it was released in March 2003, Batman: Dark Tomorrow had spent four years in development (Clow 2016; IGN Staff 2001; Speer 2006).

In addition to preview events, Kemco promoted Batman: Dark Tomorrow with a two-issue comic book prequel. This collaboration with DC and Peterson added to the project's legitimacy. Reflecting the game's dual address to gamers and comics fans, the first issue arrived as a supplement to gaming magazines like Nintendo Power and GamePro in November 2002, and the second issue appeared as a pack-in with the game itself. As Glenn Halseth, Kemco's vice president of sales and marketing, stated in a press release: "Creating this custom, limited-edition collectible comic book assures core gamers and Batman fans alike that we are developing and publishing a game that will represent Batman as intended by his original creators" (Kombo 2012, n.p.). Despite representing Batman: Dark Tomorrow's only form of transmedia storytelling expansion, these comics add little to the game's narrative. What story exists merely serves as a vehicle for Batman to encounter a collection of familiar characters. Structurally, the two comics rely on foreshadowing to remind readers of their marketing function as prequels intended to tie-in to a videogame (see Figure 11.6).

In addition to the heavy-handedness of this foreshadowing, the comics fail as transmedia in other areas as well. Specifically, not only do some aspects in the game and the comics contradict each other, but the game also neglects 


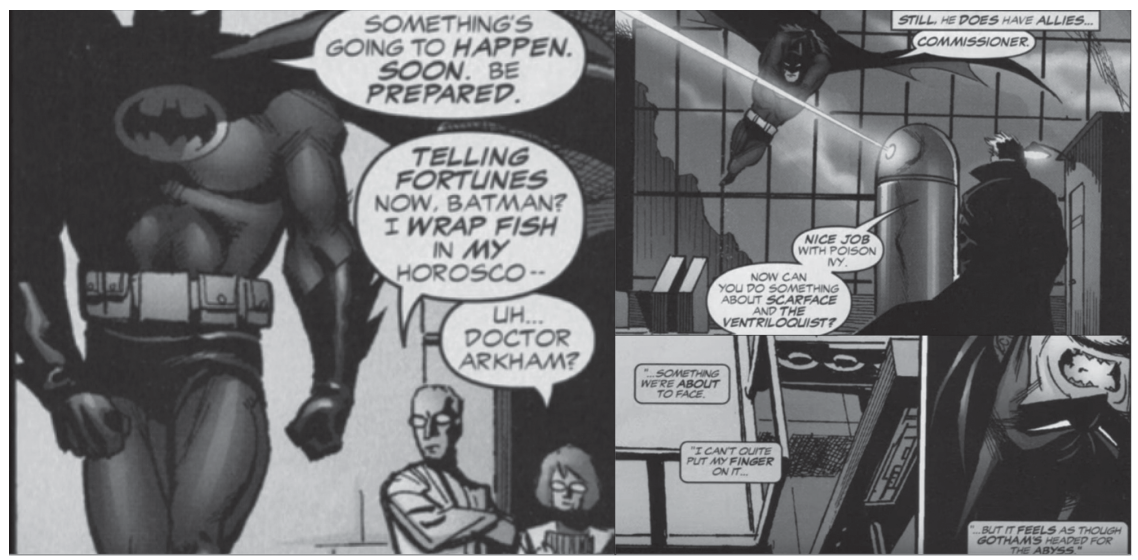

Figure 11.6 Examples of foreshadowing in the Batman: Dark Tomorrow comic books (composite by the author).

to reference events covered in the comics. For instance, both the game and the first issue of the comic feature a flashback depicting the murder of Thomas and Martha Wayne; however, the killer uses a different type of gun in the game compared to the comic book. Additionally, even though Killer Croc is hospitalized after a fight with Batman in the second prequel comic, in the videogame, he and Batman fight again with no reference to their recent duel or his hospitalization. This all suggests a lack of coordination between the videogame and comic book teams and, therefore, indicates the practical challenges of implementing a transmedia project centered on narrative extension rather than world-building.

In several respects, Batman: Dark Tomorrow ultimately failed to live up to its gaming press hype or to its comic book origins. As M. J. Clarke (2013) has noted of transmedia TV videogame tie-ins, paratexts tend to bear the marks of their production context. First, Kemco had announced back at E3 2001 that it would follow an ambitious open-world format, with Batman able to freely explore Gotham City in various vehicles like the Batmobile and Batplane. However, the finished product features strictly linear gameplay and no vehicle segments aside from a sequence in which Batman uses a hang-glider. The developers proved unable to realize this ambition, even with the delayed release date-potentially due to competing stakeholder demands.

Second, Batman: Dark Tomorrow presents one of four closing cutscenes following the final level. These endings depend on the player taking certain actions in this level, namely preventing Ra's al Ghul from detonating a series of bombs placed around the world and also defeating Ra's in a sword fight. If the player does not succeed in either of these situations, Batman dies from 
a stab wound and Ra's attains world domination. The other bleak endings feature Batman either dying or failing to save the world (even the version in which Batman only loses in battle shows that the explosions merely have been delayed by seventeen hours). In the victorious ending, Batman both saves the world and wins the duel, while Ra's accidentally dies at the hand of his own sword; however, so as to not kill off a major villain and thereby dictate the continuity of the comic book supertext going forward, Talia al Ghul revives her father in the "Lazarus Pit" after promising Batman: "We shall meet again." Although the opportunity for different endings provides a sense of variety, the game does not make clear how to achieve the victorious variation. Without consulting a gameplay "walkthrough" (i.e., a guide that explains how to progress), the player would not realize the necessity of disarming the bombs' signal device prior to the sword fight with Ra's. Because of this, the player initially will either lose entirely or defeat Ra's but not stop the bombs; at best, then, as Ra's says in the accompanying cutscene, Batman will "have won the battle, but ... lost the war." Although the script may provide the requisite high stakes expected in a Batman narrative, the lack of player instruction reflects the flawed game design and troubled development of Batman: Dark Tomorrow.

Third, the game lacks camera controls and instead features "fixed" angles whereby the player can adjust the Batman avatar but not the position of the camera. Likely implemented as a strategy to reduce development time, the changing perspective that occurs with each new screen creates a disconnect between the direction the player's thumb moves and that of the avatar. With each screen, the player will need to reorient in order to navigate Batman. When coupled with the unresponsive controls, the fixed camera renders narrative progression nearly impossible. Both of these flaws also make Batman appear inept, having seemingly lost his ability to swing across rooftops or even defend himself against generic goons.

With such an inept presentation of Batman, the game fails to capture the core of the character, despite the visuals presenting an aesthetic authentic to the comics of the time. As a frustrating gaming experience and as a problematic adaptation of the comic book storyworld, Batman: Dark Tomorrow achieves what Trevor Elkington has termed "negative synergy" (2009, 222). In other words, it fails to please either players or fans of the source material. Even with the promising presentation and concept that appeared in prerelease material, once Batman: Dark Tomorrow became playable, it joined a long line of poorly received Batman games.

Nonetheless, Batman: Dark Tomorrow represents a precursor to the direction of the Arkhamverse. In 2004-following the release of Batman: Dark Tomorrow and other maligned licensed titles like Superman: The New Superman Adventures (1999)-Time Warner formed WBIE as a videogame subsidiary of Warner Bros. Significantly, with WBIE, Warner Bros. became the first Hollywood studio to maintain an in-house game division (Fritz 2005). In contrast, other media conglomerates had traditionally kept their 


\section{J. Fleury}

videogame units separate from their film studios and even used different names to distinguish between them (e.g., Columbia Pictures and Sony Imagesoft). This corporate positioning underscored that Warner Bros. had established WBIE to control the use of its IP in licensed games-in addition to taking advantage of the fact that, as Randy Nichols $(2008,132)$ points out, games revenues had continued to outpace those of the American film industry by 2004. To increase its chances of success, Time Warner installed games industry veteran Jason Hall, co-founder of Monolith Productions, as the head of WBIE; in the past, media conglomerate-owned game divisions (e.g., Atari at WCI) typically hired executives from outside the games industry. With Hall's guidance, WBIE worked to improve the reputation of Warner IP among players by instituting a policy in 2004 that tied vendors' royalties to review scores (Gaudiosi 2004). By the time Batman: Arkham Asylum arrived five years later, WBIE also had reduced its reliance on licensing by moving into game development itself. Because of the negative critical and commercial reception it and other licensed games had received in the early 2000s, Batman: Dark Tomorrow inspired WBIE to take more control over the use of its IP in videogames.

By 2009, licensed games were beginning to move away from direct adaptations of films and TV series in favor of Batman: Dark Tomorrow's more general approach to IP. To minimize risk and to account for the migration of tie-ins to mobile platforms, WBIE started to follow a bifurcated strategy for its home console products (Batchelor 2012)..$^{7}$ On the one hand, its family-friendly $L E G O$ titles have served as tie-ins directly related to films (e.g., LEGO Harry Potter: Years 5-7 [2011] adapted the last four Harry Potter cinematic installments while also cross-promoting the home video release of Harry Potter and the Deathly Hallows-Part 2 [2011]). On the other hand, games intended for an older, "core" demographic have taken an approach that WBIE's Senior Vice President of International Games Olivier Wolff has explained as "a gaming expression of an IP which stands by itself" (Weber 2013). These games, including the Arkhamverse series and Middleearth: Shadow of Mordor (2014), function independently from other media within their respective franchises. Like Batman: Dark Tomorrow, Batman: Arkham Asylum originally had embraced a generic adaptation approach due to its publisher-Eidos-having only the DC Comics license while Electronic Arts retained the film license from Warner Bros. ${ }^{8}$

Although both Batman: Dark Tomorrow and Batman: Arkham Asylum relied on the Batman comic book license and not on the films, they met drastically different receptions, with Batman: Dark Tomorrow, Game Informer's 0.75 -out-of-10 review criticizing the gameplay as "incomprehensible and littered with bugs" (Reiner 2003, n.p.) and even IGN's slightly more optimistic 2.2-out-of-10 review concluding: "This game is crap" (Goldstein 2003, n.p.). By contrast, Game Informer called Batman: Arkham Asylum "The Best Batman Game Ever Made" (Reiner 2009, n.p.), and IGN's 9.3out-of-10 review referred to it as "the greatest comic book videogame of all 
time" (Miller 2010, n.p.). Like Batman: Dark Tomorrow, Batman: Arkham Asylum and its sequels debuted in years devoid of a Batman film and worked to keep the character in the public consciousness. Whereas tie-ins previously had served as multimedia paratexts to Batman films, the Arkham gamesas centers of a unique supertext-represented transmedia mothership texts supported by their own paratexts. This suggests how WBIE positioned each Arkhamverse game as a blockbuster entertainment in its own right whereas Batman: Dark Tomorrow's development and marketing issues suggest a lack of care on behalf of DC Comics and Time Warner.

Furthermore, while Batman: Dark Tomorrow represents a Batman videogame supertext prototype, its transmedia presence was limited only to the comics. Not only does the game's content reflect only the comics of the time, but also its transmedia extensions include just the two prequel comics. Batman: Arkham Asylum, both diegetically and extradiegetically, represents a much more ambitious venture. On the level of content, the open-world Batman: Arkham Asylum and the larger Arkhamverse leverage the inherent multiplicity of the Batman megatext that had become increasingly prevalent since the 1980s. Whereas Batman: Dark Tomorrow presents only the comic book incarnation, the Arkhamverse consolidates material from multiple Batman media to form what Kalvero A. Sinervo has described as a "palimpsest" (2016). In his transmedia storytelling guide Comics for Film, Games and Animation: Using Comics to Construct Your Transmedia Storyworld (2013), Tyler Weaver presents a case study of Batman: Arkham City (2011), the second game released as part of the Arkhamverse. He notes, "Arkham Asylum created an entirely new Batman storyworld, one that blended the best of the comics with the best of the movies and the best of the animated incarnation" (Weaver 2013, 247). This description emphasizes how the Arkhamverse consolidates not just any element from across the Batman megatext but specifically those elements that fans tend to regard as "the best," such as acting and writing talent from Batman: The Animated Series, the tone of the Dark Knight film trilogy, and characters and locations derived from the comic books. Compared to Batman: Dark Tomorrow, the Arkhamverse presents a much more expansive transmedia storytelling context spread across comic books, mobile apps, a virtual reality experience, and a direct-to-video animated film (see Figure 11.7).

\section{Conclusion}

Even though videogame players and Batman fans have long criticized Batman: Dark Tomorrow, it nonetheless inspired-however indirectlythe transmedia approach of the Arkhamverse. ${ }^{9}$ From this perspective, Batman: Dark Tomorrow provides the opportunity for a media industries failure study. Matt Hills (2013) and John Thornton Caldwell (2015) have advocated for looking at examples of failure, such as discontinued products or incompatible production cultures, to gain insight on what does not work. 


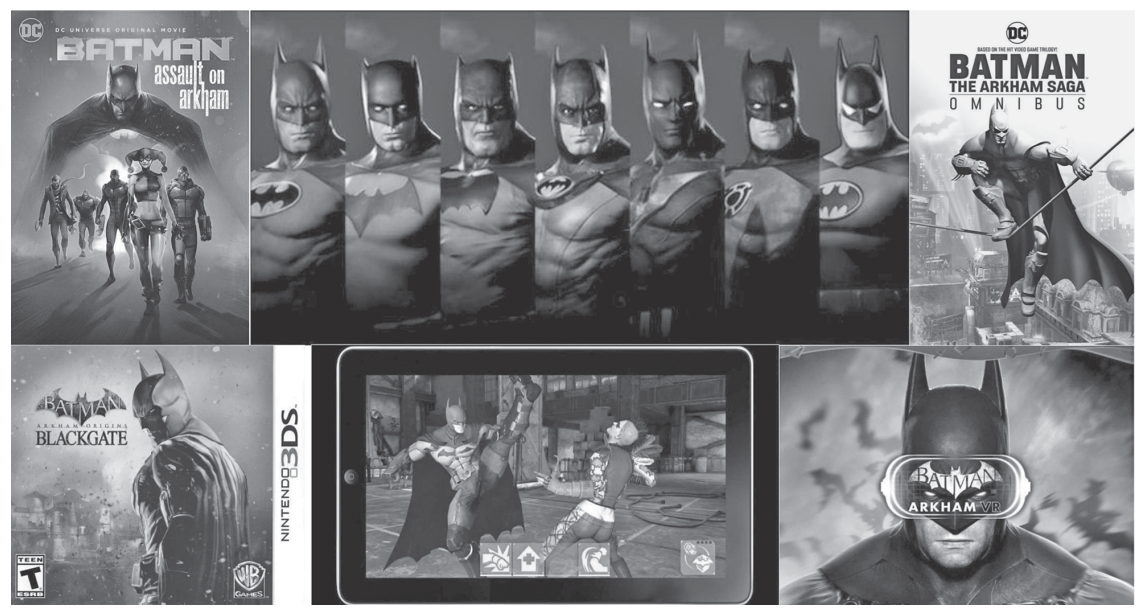

Figure 11.7 Transmedia components of the Arkhamverse (composite by the author).

In particular, Batman: Dark Tomorrow demonstrated how a videogame could stand apart from other Batman media and form the center of its own transmedia supertext. With the Arkhamverse, the games represent the central, mothership text and not an ancillary like a traditional tie-in. More broadly, Batman: Arkham Asylum inspired WBIE to approach its IP-based games as distinct; according to Senior Vice President of Digital Gaming Glen Ballard, they "transcend" individual films, such that games featuring a particular IP can adapt a megatext instead of needing to adapt an individual supertext or text featuring that IP. For WBIE, then, the Arkhamverse has demonstrated that licensed games can achieve success without explicit textual connections. Just as its licensing penalty had helped legitimize WBIE and the gaming presence of Warner brands, so has the decision to position its games as distinct from other media. Beyond legitimization, the generic adaptation approach helps to promote multiple, related media through a single text. 2015's Batman: Arkham Knight, for instance, features content related to the TV series Batman, comic book arcs like Batman: Under the Red Hood (2004-2006), and films like Batman v Superman: Dawn of Justice (2016) (IGN 2016).

Batman: Dark Tomorrow showed how videogames like Batman: Arkham Asylum could help maintain brand awareness in years without Batman film installments and thereby stimulate sales of previous texts and paratexts. In other words, the generic approach provides these games with a timeless quality that can benefit from, but does not necessarily depend on, the marketing hype for another, related product like a theatrical film release. Other licensors have adopted this approach; for Sony and Marvel, the PlayStation 4-exclusive Marvel's Spider-Man (2018) does not directly adapt 
any pre-existing Spider-Man text but instead integrates elements from across the character's megatext. As such, it sustained public awareness about the character in advance of his next film appearance while also driving audiences to other Spider-Man texts. General adaptations like these contrast early media-licensed games from the Atari 2600 era (e.g., 1978's Superman), when limited technology meant providing a small narrative around gameplay. Today, the open-world Arkham games and Marvel's Spider-Man demonstrate how contemporary media-licensed software tends to place gameplay over an expansive, multistory narrative.

Despite its perceived failures, Batman: Dark Tomorrow did succeed in sustaining the Batman megatext in between film releases. Its greatest legacy lay in disconnecting from the Batman films or animated series and in demonstrating how a videogame could launch a transmedia extension. In both of these ways, the transitional paratext of Batman: Dark Tomorrow paved the road to Batman: Arkham Asylum and a more expansive transmedia enterprise.

\section{Notes}

1 Internet Service Provider AOL and the Time Warner media conglomerate merged in 2000; however, due to AOL's loss of market value, the corporate masthead reverted back to "Time Warner" in 2003. In 2009, Time Warner divested itself of AOL.

2 The Superman comics exploited the film's marketing hype by reintegrating previously abandoned elements, such as a weakness to kryptonite and Clark Kent's role as a newspaper reporter at The Daily Planet (Tye 2012, 544).

3 As Boni writes, "the elements of transmedia storytelling all too often remain part of a designed, top-down experience. Commercial transmedia worlds are often built upon a deterministic vision" $(2017,17)$.

4 See, for instance, Elkington 2009, who argues that story in tie-ins typically takes precedence over gameplay.

5 This recalls the multiquadrant demographic targeting strategies that blockbuster films often employ, such as 1989 's Batman appealing to older audiences with a decades-old IP and the casting of Jack Nicholson as well as appealing to young audiences with a young director, Tim Burton, and original music from Prince.

6 Pitts notes that publishers at preview events tend to use the highest-quality hardware within a strictly controlled environment. He warns: "Suffice it to say, take previews with a grain of salt" (Pitts 2016, 132).

7 As an executive from Ubisoft explains: "In our industry, product development is expensive, which means that along with big opportunities there are significant industrial risks [...] World-famous and high-potential IPs aimed at dedicated targets (kids, young male adults, etc.) usually allow a minimisation of these risks" (Batchelor 2012).

8 Electronic Arts held the rights to adapt the Dark Knight film trilogy; however, the publisher released only a 2005 tie-in to Batman Begins and canceled development on a game based on The Dark Knight. By the time The Dark Knight Rises was released in 2012, Electronic Arts had lost the rights to the Batman film license; 


\section{J. Fleury}

instead, the film's tie-in arrived only on phones and tablets, from mobile developer and publisher Kabam.

9 For examples of critical perspectives on Batman: Dark Tomorrow, see Psykhophear 2008; and Crappy Games Wiki Uncensored 2018.

\section{Works cited}

The Amazing Spider-Man. 2012. Developed by Beenox. Published by Activision. PlayStation 3.

The Amazing Spider-Man 2. 2014. Dir. Marc Webb. USA: Sony Pictures.

Aquaman: Battle for Atlantis. 2003. Developed by Lucky Chicken Games. Published by TDK Interactive. GameCube.

Batchelor, James. 2012. "Ubisoft: Strong Licences Need Strong Concepts." MCV, 20 December. www.mcvuk.com/ubisoft-strong-licences-need-strong-concepts/ (accessed 31 January 2020).

Batman. 1989. Dir. Tim Burton. USA: Warner Bros. Pictures.

Batman: Arkham Asylum. 2009. Developed by Rocksteady Studios. Published by Eidos Interactive and Warner Bros. Interactive Entertainment. PlayStation 3.

Batman: Arkham City. 2011. Developed by Rocksteady Studios. Published by Warner Bros. Interactive Entertainment. PlayStation 3.

Batman: Arkham Knight. 2015. Developed by Rocksteady Studios. Published by Warner Bros. Interactive Entertainment. Xbox One.

Batman: The Caped Crusader. 1988. Developed by Special FX Software Ltd. Published by Data East. MS-DOS.

Batman: Dark Tomorrow. 2003. Developed by Hot Gen. Published by Kemco. GameCube.

Batman: Return of the Joker. 1991. Developed and published by Sunsoft. Nintendo Entertainment System.

Batman: Rise of Sin Tzu. 2003. Developed and published by Ubisoft. GameCube.

Batman: Vengeance. 2001. Developed and published by Ubisoft. GameCube.

Batman: The Video Game. 1990. Developed and published by Sunsoft. Nintendo Entertainment System.

Batman and Robin. 1997. Dir. Joel Schumacher. USA: Warner Bros. Pictures.

Batman Begins. 2005. Developed by Eurocom. Published by Electronic Arts. PlayStation 2.

Batman Begins. 2005. Dir. Christopher Nolan. USA: Warner Bros. Pictures.

Batman Forever. 1995. Dir. Joel Schumacher. USA: Warner Bros. Pictures.

Batman Returns. 1992. Dir. Tim Burton. USA: Warner Bros. Pictures.

Boni, Marta. 2017. "Introduction.” In World Building: Transmedia, Fans, Industries, edited by Marta Boni, 9-27. Amsterdam: Amsterdam University Press.

Browne, Nick. 1984. "The Political Economy of the Television (Super) Text." Quarterly Review of Film and Video 9 (3): 174-182.

Caldwell, John Thornton. 2015. "Production Studies: Where Do We Go from Here?" Paper presented at the Conference of New Directions in Film and Television Production Studies, 14-15 April, Bristol, UK.

Clarke, M. J. 2013. Transmedia Television: New Trends in Network Serial Production. New York: Bloomsbury.

Clow, Chris. 2016. "Batman: Dark Tomorrow (with Special Guest Scott Peterson).” Comics on Consoles, 26 March. Podcast. 
Crappy Games Wiki Uncensored. 2018. “Batman: Dark Tomorrow.” Crappy Games Wiki Uncensored,26 July.https://crappygames.miraheze.org/wiki/Batman:_Dark_ Tomorrow (accessed 31 January 2020).

The Dark Knight. 2008. Dir. Christopher Nolan. USA: Warner Bros. Pictures.

The Dark Knight Rises. 2012. Dir. Christopher Nolan. USA: Warner Bros. Pictures.

The Death and Return of Superman. 1994. Developed by Blizzard Entertainment. Published by Sunsoft. SNES.

Elkington, Trevor. 2009. "Too Many Cooks: Media Convergence and Self-Defeating Adaptations." In The Video Game Theory Reader 2, edited by Bernard Perron and Mark J. P. Wolf, 213-235. New York: Routledge.

Enter the Matrix. 2003. Developed by Shiny Entertainment. Published by Atari. GameCube.

Fast, Kristin, and Henrik Örnebring. 2017. "Transmedia World-Building: The Shadow (1931-Present) and Transformers (1984-Present)." The International Journal of Cultural Studies 20 (6): 636-652.

Fleury, James, Bryan Hikari Hartzheim, and Stephen Mamber. 2019. "Introduction: The Franchise Era." In The Franchise Era: Managing Media in the Digital Economy, edited by James Fleury, Bryan Hikari Hartzheim, and Stephen Mamber, 1-28. Edinburgh: Edinburgh University Press.

Flint, Joe. 2019. "AT\&T to HBO, Turner: No More Fiefdoms.” The Wall Street Journal, 1 March. www.wsj.com/articles/at-t-readying-overhaul-of-warnermedia11551483138 (accessed 31 January 2020).

Freeman, Matthew. 2016. Historicising Transmedia Storytelling: Early TwentiethCentury Transmedia Story Worlds. New York: Routledge.

Freeman, Matthew. 2017. "From Sequel to Quasi-Novelization: Splinter of the Mind's Eye and the 1970s Culture of Transmedia Contingency." In Star Wars and the History of Transmedia Storytelling, edited by Sean Guynes and Dan HasslerForest, 61-72. Amsterdam: Amsterdam University Press.

Fritz, Ben. 2005. "Warner Plays Its Own Game.” Variety, 9 January. https://variety. com/2005/film/news/warners-plays-its-own-game-1117915856/ (accessed 31 January 2020).

Gaudiosi, John. 2004 "Warner Interactive Aims for Better Film-Game Synergy." Home Media Magazine, 19 July. https://web.archive.org/web/20160303221353/ www.homemediamagazine.com/news/warner-interactive-aims-better-film-gamesynergy-6420 (accessed 31 January 2020).

Goldstein, Hilary. 2003. "Batman: Dark Tomorrow Review.” IGN, 24 March. www.ign.com/articles/2003/03/24/batman-dark-tomorrow-review (accessed 31 January 2020).

Guynes, Sean, and Dan Hassler-Forest. 2017. "Introduction: What Is This Strange World We've Come To?" In Star Wars and the History of Transmedia Storytelling, edited by Sean Guynes and Dan Hassler-Forest, 11-13. Amsterdam: Amsterdam University Press.

Harry Potter and the Deathly Hallows-Part 2. 2011. Dir. David Yates. USA: Warner Bros. Pictures.

Hills, Matt. 2013. “TV Aesthetics in Transition: 'Bad' TV Dramas and Discourses of Failure.” Paper presented at the Society for Cinema and Media Studies Conference, 7 March, Chicago, US.

IGN. 2016. “Batman Arkham Knight Wiki Guide.” IGN, 3 November. www.ign. com/wikis/batman-arkham-knight/ (accessed 31 January 2020). 


\section{J. Fleury}

IGN Staff. 2001. “Tomorrow Delayed.” IGN, 25 September. https://au.ign.com/ articles/2001/09/25/tomorrow-delayed (accessed 31 January 2020).

Jenkins, Henry. 2006. Convergence Culture: Where Old and New Media Collide. New York: New York University Press.

Jenkins, Henry. 2009a. "The Many Lives of the Batman (Revisited): Multiplicity, Manga, and Anime." Confessions of an Aca-Fan, 2 February. http://henryjenkins. org/blog/2009/02/the_many_lives_of_the_batman_r.html (accessed 31 January 2020).

Jenkins, Henry. 2009b. "The Revenge of the Origami Unicorn: Seven Principles of Transmedia Storytelling." Confessions of an Aca-Fan, 12 December. http://henryjenkins.org/blog/2009/12/the_revenge_of_the_origami_uni.html (accessed 31 January 2020).

Jenkins, Henry. 2014. "The Reign of the Mothership: Transmedia's Past, Present, and Possible Futures." In Wired TV: Laboring over an Interactive Future, edited by Denise Mann, 244-268. New Brunswick: Rutgers University Press.

Kinder, Marsha. 1991. Playing with Power in Television, Movies and Video Games: From Muppet Babies to Teenage Mutant Ninja Turtles. Berkeley: University of California Press.

Kohler, Chris. 2013. "Why Games Based on Movies Disappeared (and Why They're Coming Back).” Wired, 15 February. www.wired.com/2013/02/movie-games/ (accessed 31 January 2020).

Kombo. 2012. "Kemco and DC Comics to Create Limited Edition Comic Book for 'Batman: Dark Tomorrow.'” GameZone, 4 May. www.gamezone.com/originals/ kemco-and-dc-comics-to-create-limited-edition-comic-book-for-quot-batmandark-tomorrow-39/ (accessed 31 January 2020).

LEGO Harry Potter: Years 5-7. 2011. Developed by Traveller's Tales. Published by Warner Bros. Interactive Entertainment. PlayStation 3.

Littleton, Cynthia. 2013. "Warner Bros. Embraced Digital Future with Choice of Kevin Tsujihara as CEO.” Variety, 27 March. https://variety.com/2013/biz/ news/warner-bros-embraces-digital-future-in-selecting-kevin-tsujihara-as-ceo1200328738/ (accessed 31 January 2020).

Marvel's Spider-Man. 2018. Developed by Insomniac Games. Published by Sony Interactive Entertainment. PlayStation 4.

Meehan, Eileen. 2015. “'Holy Commodity Fetish, Batman!': The Political Economy of a Commercial Intertext." In Many More Lives of the Batman, edited by Roberta E. Pearson, William Uricchio, and Will Brooker, 69-87. New York: Palgrave Macmillan.

Middle-earth: Shadow of Mordor. 2014. Developed by Monolith Productions. Published by Warner Bros. Interactive Entertainment. Xbox One.

Miller, Greg. 2010. "Batman: Arkham Asylum (Game of the Year) Review." IGN, 26 May. www.ign.com/articles/2010/05/27/batman-arkham-asylum-game-of-theyear-review (accessed 31 January 2020).

Nichols, Randy. 2008. "Ancillary Markets: Merchandising and Video Games." In The Contemporary Hollywood Film Industry, edited by Janet Wasko and Paul McDonald, 132-142. Malden: Wiley-Blackwell.

Parody, Clare. 2011. “Franchising/Adaptation.” Adaptation 4 (2): 210-218.

Pearson, Roberta E. 2017. "World-Building Logics and Copyright: The Dark Knight and the Great Detective." In World Building: Transmedia, Fans, Industries, edited by Marta Boni, 109-128. Amsterdam: Amsterdam University Press. 
Pitts, Russ. 2016. Sex, Drugs, and Cartoon Violence: My Decade as a Video Game Journalist. Self-published.

Psykhophear. 2008. "Possibly the Worst Batman Game You'll Ever Play." Giant Bomb, 5 December.

Reiner, Andrew. 2003. “Batman: Dark Tomorrow (GC).” Game Informer 121: 87.

Reiner, Andrew. 2009. "Batman: Arkham Asylum." Game Informer, 27 September.

Ryan, Marie-Laure, and Jan-Noël Thon. 2014. "Storyworlds across Media: Introduction." In Storyworlds across Media: Toward a Media-Conscious Narratology, edited by Marie-Laure Ryan and Jan-Noël Thon, 1-21. Lincoln: University of Nebraska Press.

Screen International. 1978. "Selling 'Superman,” Screen International (9 December): 12.

Sinervo, Kalervo A. 2016. "Gotham on the Ground: Transmedia Meets Topography in the Environments of the Arkham Videogame Series." Wide Screen Journal 6 (1): n.p. http://widescreenjournal.org/index.php/journal/article/view/103/140 (accessed 31 January 2020).

Speer, Justin. 2006. "E3 2001 First Impression: Batman: Dark Tomorrow." GameSpot, 17 May.

Spider-Man. 2002. Developed by Treyarch. Published by Activision. GameCube.

Spider-Man and Venom: Maximum Carnage. 1994. Developed by Software Creations. Published by LJN. SNES.

Star Wars Episode I: The Phantom Menace. 1999. Dir. George Lucas. USA: 20th Century Fox.

Star Wars Episode VI: Return of the Jedi. 1983. Dir. Richard Marquand. USA: 20th Century Fox.

Superman. 1978. Developed and published by Atari. Atari 2600.

Superman: The Man of Steel. 2002. Developed by Circus Freak. Published by Infogrames. Xbox.

Superman: The Movie. 1978. Dir. Richard Donner. USA: Warner Bros. Pictures.

Superman: The New Superman Adventures. 1999. Developed and published by Titus Interactive. Nintendo 64.

Tye, Larry. 2012. Superman: The High-Flying History of America's Most Enduring Hero. New York: Random House.

Uricchio, William, and Roberta E. Pearson. 2015. "I'm Not Fooled by That Cheap Disguise." In Many More Lives of the Batman, edited by Roberta E. Pearson, William Uricchio, and Will Brooker, 205-236. New York: Palgrave Macmillan.

Weaver, Tyler. 2013. Comics for Film, Games and Animation: Using Comics to Construct Your Transmedia Storyworld. New York: Focal Press.

Weber, Rachel. 2013. "Warner's Wolff: 'We Really Have a Competitive Advantage."” GamesIndustry.biz, 7 October. www.gamesindustry.biz/articles/2013-10-07olivier-wolff (accessed 31 January 2020).

Zahn, Timothy. 1991. Heir to the Empire. New York: Bantam Spectra. 